\title{
Experimental and theoretical study of the electronic structures of $\mathrm{Ni}_{3} \mathrm{Al}$, $\mathrm{Ni}_{3} \mathrm{Ga}, \mathrm{Ni}_{3} \mathrm{In}$, and $\mathrm{NiGa}$
}

\author{
Li-Shing Hsu \\ Department of Physics, National Chang-Hua University of Education, Chang-Hua 50058, Taiwan, \\ Republic of China \\ Y.-K. Wang \\ Department of Physics, National Taiwan University, Taipei 107, Taiwan, Republic of China \\ G. Y. Guo \\ Department of Physics, National Taiwan University, Taipei 107, Taiwan, Republic of China \\ and Synchrotron Radiation Research Center, Hsinchu 300, Taiwan, Republic of China
}

(Received 12 February 2002; accepted for publication 8 May 2002)

\begin{abstract}
The electronic structures of $\mathrm{Ni}_{3} \mathrm{Al}, \mathrm{Ni}_{3} \mathrm{Ga}, \mathrm{Ni}_{3} \mathrm{In}$, and $\mathrm{NiGa}$ are studied by $\mathrm{x}$-ray absorption near-edge spectra (XANES) at the $\mathrm{Ni}$ and $\mathrm{Ga} K$ edges. The XANES spectra are compared with those calculated with theory. The experimental XANES features for these compounds reflect the Ni- and Ga- $p$ unoccupied density of states. The calculated magnetic moments for $\mathrm{Ni}_{3} \mathrm{Al}, \mathrm{Ni}_{3} \mathrm{Ga}$, and $\mathrm{Ni}_{3} \mathrm{In}$ are between $0.7-0.8 \mu_{\mathrm{B}} /$ cell. The number of $3 d$ holes per $\mathrm{Ni}$ atom is calculated for $\mathrm{Ni}_{3} \mathrm{Al}_{1} \mathrm{Ni}_{3} \mathrm{Ga}$, and $\mathrm{Ni}_{3} \mathrm{In}$. These numbers show correlation with heats of formation of the bulk compounds. (C) 2002 American Institute of Physics. [DOI: 10.1063/1.1491018]
\end{abstract}

\section{INTRODUCTION}

Binary intermetallic compounds that contain a transition metal and a group-III metal display interesting electronic and magnetic properties. For instance, the stoichiometric compound $\mathrm{Ni}_{3} \mathrm{Al}$ shows weak itinerant ferromagnetism with $T_{c}$ $=41.5 \mathrm{~K}$ and a very small magnetic moment $\left(0.23 \mu_{\mathrm{B}}\right.$ per cell), ${ }^{1}$ the stoichiometric compound $\mathrm{Ni}_{3} \mathrm{Ga}$ is an exchangeenhanced paramagnetic metal, ${ }^{1-3}$ and $\mathrm{NiGa}$ is nonmagnetic. In this article, $\mathrm{x}$-ray absorption near-edge spectra (XANES) at the $\mathrm{Ni}$ and $\mathrm{Ga} K$ edges of four intermetallic compounds $\left(\mathrm{Ni}_{3} \mathrm{Al}, \mathrm{Ni}_{3} \mathrm{Ga}, \mathrm{Ni}_{3} \mathrm{In}\right.$, and $\left.\mathrm{NiGa}\right)$ were measured and compared with theoretical XANES spectra. Such analysis is especially important for establishing a relationship between the experimental XANES spectra and the unoccupied part of the local density of states (DOS) and obtaining quantitative information about hole numbers and charge transfer in these intermetallic compounds. Experimental Ni $L_{2,3}$-edge and $\mathrm{Al}$ and $\mathrm{Ni} K$-edge XANES spectra of $\mathrm{Ni}_{3} \mathrm{Al}^{4},{ }^{4-8} \mathrm{Ni}_{3} \mathrm{Ga},{ }^{5-7,9}$ $\mathrm{Ni}_{3} \mathrm{In}^{7}$ and $\mathrm{NiGa}^{7,9}$ have been reported previously. The $\mathrm{Ni}$ $L_{2,3}$ near-edge structures of $\mathrm{Ni}_{3} \mathrm{Al}$ were also measured by electron-energy-loss spectroscopy. ${ }^{10,11}$ Theoretical analyses of the Ni $L_{2,3}$-edge and $\mathrm{Al}$ and $\mathrm{Ni} K$-edge XANES spectra have been performed on $\mathrm{Ni}_{3} \mathrm{Al},{ }^{6,7,8} \mathrm{Ni}_{3} \mathrm{Ga},{ }^{6,7} \mathrm{Ni}_{3} \mathrm{In},{ }^{7}$ and $\mathrm{NiGa}^{7}$ using either band-structure or multiple-scattering method. Another purpose of this article is to systematically study the electronic structures and the mechanical and magnetic properties of a series of technologically interesting intermetallic compounds, and to compare with available experimental and theoretical results. We note that very few studies were done on $\mathrm{Ni}_{3} \mathrm{In}$ and $\mathrm{NiGa}$.

This article is organized as follows. In Sec. II, the experimental and the theoretical methods are described. In Sec. III, the results and discussion are presented. The conclusions of this work are contained in Sec. IV.

\section{METHODS}

\section{A. Experimental methods}

Preparation and characterization of polycrystalline samples of $\mathrm{Ni}$ intermetallic compounds were reported previously. ${ }^{4,12}$ Energy-dispersive x-ray (EDX) analysis showed that the $\mathrm{Ni}$ atoms concentration deviates by 2, 0 , and $3 \%$ from the nominal compositions for $\mathrm{Ni}_{3} \mathrm{Al}, \mathrm{Ni}_{3} \mathrm{Ga}$, and $\mathrm{Ni}_{3} \mathrm{In}$, respectively; whereas they are rich by $21 \%$ for NiGa. We note that our bulk $\mathrm{Ni}_{0.73} \mathrm{Al}_{0.27}$ and $\mathrm{Ni}_{3} \mathrm{Ga}$ samples are in the paramagnetic phase. ${ }^{1}$ The residual resistivity $(\rho)$ ratio $\left(\rho_{300 \mathrm{~K}} / \rho_{4.2 \mathrm{~K}}\right)$ for $\mathrm{Ni}_{3} \mathrm{Al}$ and $\mathrm{NiGa}$ is 4.5 and $1.32,{ }^{13}$ respectively. The XANES experiments were carried out on wiggler beamline $17 \mathrm{C}$ at the Synchrotron Radiation Research Center, Taiwan. A Si(111) double-crystal monochromator was used and the typical energy resolution was about $2 \mathrm{eV}$. The XANES spectra were collected by recording the total yield of secondary electrons from the sample surfaces at room temperature. Standard 5- $\mu \mathrm{m}$-thick Ni foil was used as a reference for energy calibration. Ni XANES data were also used as a reference spectrum. Data at the $\mathrm{Ga} K$ edge for $\mathrm{Ni}_{3} \mathrm{Ga}$ and $\mathrm{NiGa}$ were internally calibrated by setting the inflection points to $10367.0 \mathrm{eV}$. The photon flux was obtained simultaneously by measuring the current of a Au mesh located near the exit slit of the monochromator and used for normalization of the XANES spectra.

\section{B. Theoretical methods}

The theoretical XANES spectra, the electronic structures, and the mechanical and magnetic properties of these intermetallic compounds are calculated using the highly accurate all-electron full-potential linear augmented-planewave (FLAPW) method. ${ }^{14}$ The calculations are based on first-principles density-functional theory with the generalized 

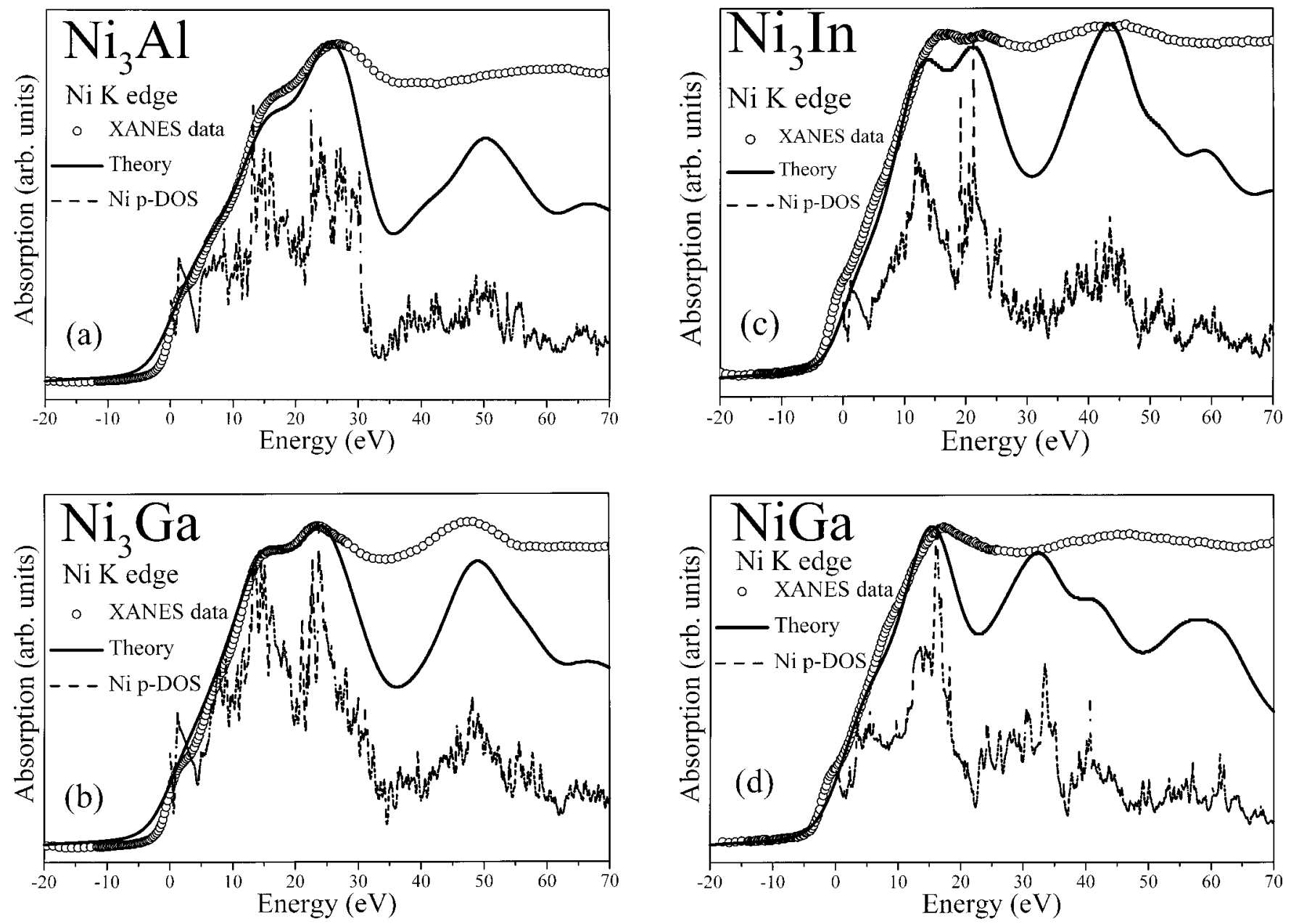

FIG. 1. The experimental (open circles) and theoretical paramagnetic (solid lines) $\mathrm{Ni} K$-edge XANES spectra for (a) $\mathrm{Ni}_{3} \mathrm{Al},\left(\right.$ b) $\mathrm{Ni}_{3} \mathrm{Ga},(\mathrm{c}) \mathrm{Ni}_{3} \mathrm{In}$, and (d) NiGa. Also shown is the Ni $p$ partial DOS (dashed lines).

gradient approximation (GGA) to the exchange-correlation potential. ${ }^{15}$ We find that using the GGA is essential to bring the calculated lattice constants and bulk moduli of these compounds into good agreement with the experimental values. We begin the calculations by determining total energies at several values of the lattice constants near the experimental one for each compound. These energies are then fitted to the Murnaghan equation of state ${ }^{16}$ to obtain the theoretical equilibrium lattice constants and bulk moduli. The calculations are done for both paramagnetic and ferromagnetic states of these materials. The muffin-tin radius of $1.22 \AA$ is used for all the atoms. The wave functions, the charge densities, and the potentials are expanded in terms of the spherical harmonics inside the muffin-tin spheres. The cutoff angular momentum $\left(l_{\max }\right)$ is ten for the wave functions and six for the charge densities and the potentials. The Brillouin zone (BZ) integration is carried out by using the improved tetrahedron method. ${ }^{17}$ The number of the augmented plane waves included is about 80 per atom, i.e., $R_{\mathrm{mt}} K_{\max }=9 .{ }^{14}$ The number of the $k$ points in the irreducible BZ wedge (IBZW) used in the self-consistent calculations is 56 . To calculate the DOS curves and the theoretical XANES spectra, the experimental lattice constants for these intermetallics and $165 k$ points in the IBZW were used. We have checked the conver- gence of the calculated eigenvalues with respect to the number of augmented plane waves used and the number of $k$ points used.

\section{RESULTS AND DISCUSSIONS}

The experimental (open circles) and theoretical paramagnetic (solid lines) XANES spectra of Ni $K$ edge for $\mathrm{Ni}_{3} \mathrm{Al}, \mathrm{Ni}_{3} \mathrm{Ga}, \mathrm{Ni}_{3} \mathrm{In}$, and NiGa are displayed in Figs. 1(a)1(d), respectively, those of $\mathrm{Ga} K$ edge for $\mathrm{Ni}_{3} \mathrm{Ga}$ and $\mathrm{NiGa}$ are shown in Figs. 2(a) and 2(b), respectively. The Ni $K$-edge XANES spectra for $\mathrm{Ni}_{3} \mathrm{Al}$ and $\mathrm{Ni}_{3} \mathrm{Ga}$ are similar to those reported previously. ${ }^{5,6,8}$ Also shown in Figs. 1 and 2 are $\mathrm{Ni}$ and Ga $p$ partial DOSs (dashed lines), respectively, calculated for these intermetallic compounds. The maxima of the XANES spectra in Figs. 1 and 2 coincide, respectively, with the peaks in the $\mathrm{Ni}$ and $\mathrm{Ga} p$ partial-DOS curves, which correspond to $\mathrm{Ni}$ and $\mathrm{Ga} 1 s$ to $\varepsilon p$ transitions. The zero energies correspond to the inflection points of the respective $\mathrm{Ni}$ and $\mathrm{Ga} K$-edge absorption edges. The experimental data were normalized to theoretical spectra in the region 10-20 $\mathrm{eV}$ above the absorption edges. The absolute energies of the $\mathrm{Ni}$ and $\mathrm{Ga} K$-edge white lines and the energy separations of the subsequent XANES structures for these four compounds 

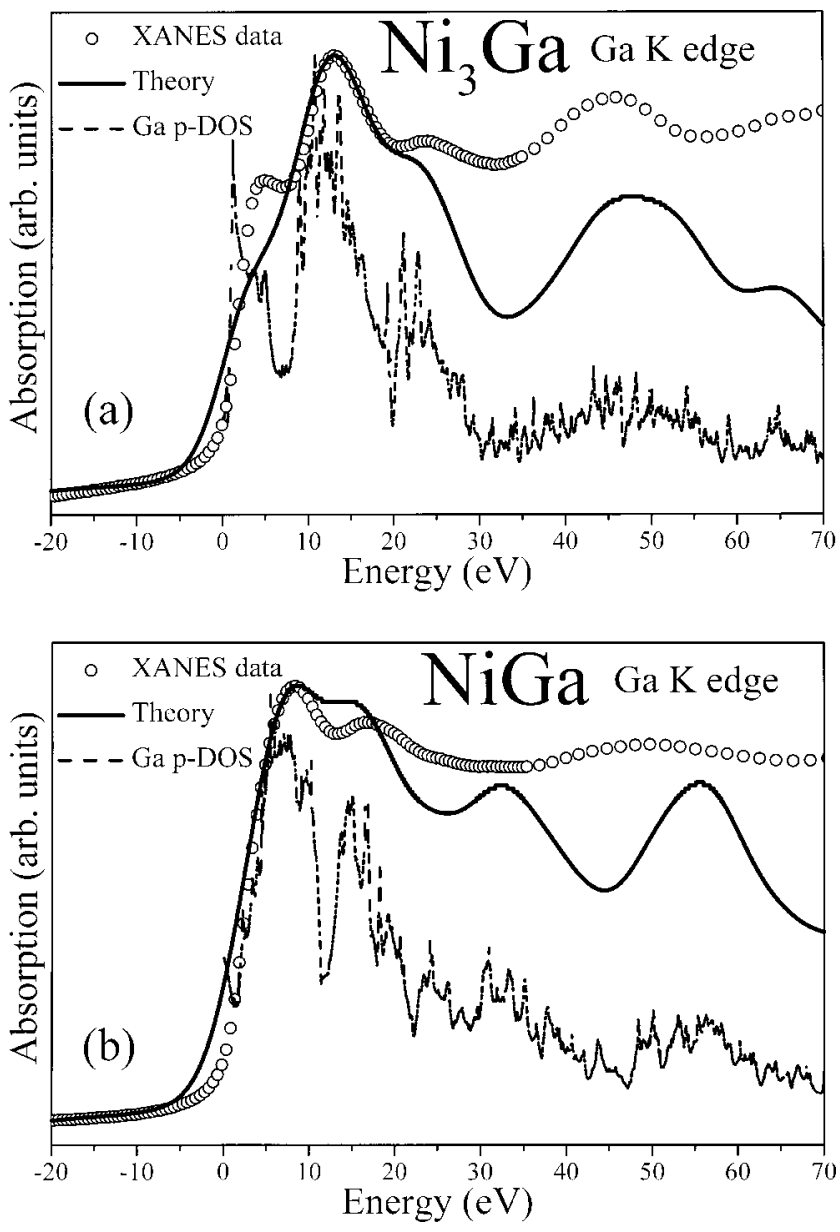

FIG. 2. Same as Fig. 1 except for Ga $K$-edge XANES spectra for (a) $\mathrm{Ni}_{3} \mathrm{Ga}$ and (b) NiGa. Also shown is the Ga $p$ partial DOS (dashed lines).

are listed in Table I. Overall, we have a reasonable good agreement between theory and experiment. The decrease in peak height after the maxima is due to the finite-sized, linearized energy-dependent basis sets in the muffin-tin spheres used in the present calculations. With the exception of $\mathrm{NiGa}$, all major features of the absorption peaks, as well as whiteline positions and intensities, are well reproduced. The disagreement between experimental and theoretical $\mathrm{Ni}$ and $\mathrm{Ga}$ $K$-edge XANES spectra found for $\mathrm{NiGa}$ is caused by high concentration of antistructure defects $(0.75$ at. \%) present in

TABLE I. The absolute energies (in eV) of the $\mathrm{Ni}$ and $\mathrm{Ga} K$-edge white lines for $\mathrm{Ni}_{3} \mathrm{Al}, \mathrm{Ni}_{3} \mathrm{Ga}, \mathrm{Ni}_{3} \mathrm{In}$, and $\mathrm{NiGa}$, and the energy separations of the subsequent XANES structures.

\begin{tabular}{lrrrr}
\hline \hline Edge & $\mathrm{Ni}_{3} \mathrm{Al}$ & $\mathrm{Ni}_{3} \mathrm{Ga}$ & $\mathrm{Ni}_{3} \mathrm{In}$ & \multicolumn{1}{c}{$\mathrm{NiGa}$} \\
\hline Ni $K$ & 8331.6 & 8331.6 & 8334.0 & 8334.0 \\
& 1.4 & 2.5 & & \\
& 16.0 & 15.5 & 15.8 & 17.3 \\
& 26.8 & 23.4 & 22.8 & \\
Ga $K$ & & 48.4 & 46.0 & 10371.7 \\
& & 10372.1 & & 3.5 \\
& & 4.9 & & 13.0 \\
& & 23.9 & & 47.7 \\
\hline \hline
\end{tabular}

the sample, ${ }^{13}$ which were not considered in the present theory. The same disagreement was also found in $\mathrm{NiGa}$ of the Ni L-edge XANES spectrum and that obtained from multiple-scattering theory. ${ }^{7}$ Small discrepancies in peak positions and intensities might be due to the use of muffin-tin approximation in calculation of the potentials and to the neglect of the dipole transition-matrix elements. For example, the theoretical $\mathrm{Ni} K$-edge XANES spectra for $\mathrm{Ni}_{3} \mathrm{Al}$ and $\mathrm{Ni}_{3} \mathrm{Ga}$ well produce the three experimental peaks at approximately 16, 25, and $49 \mathrm{eV}$ above the white lines. The same features are present in the calculated $\mathrm{Ni} K$-edge XANES spectra for $\mathrm{Ni}_{3} \mathrm{In}$, though less pronounced and in less agreement with the experimental data of the peak positions. Another source of error is that the GGA eigenvalues are not the true excitations of the XANES spectra, and the errors in peak positions are comparable to the self-energy correction between GGA and more sophisticated methods such as GW. ${ }^{18}$ As for the source of the discrepancy in peak width, the hotelectron lifetime is strongly energy dependent so that it mostly damps peaks about $20 \mathrm{eV}$ above the absorption edge. Since the dipole transition-matrix element is not a very sharp function of energy above $40 \mathrm{eV}$ of the $\mathrm{Ni}-K$ white line for $\mathrm{Ni}_{3} \mathrm{Al},{ }^{8}$ the difference in intensity of the XANES features at roughly $49 \mathrm{eV}$ above the $\mathrm{Ni}-K$ white lines for $\mathrm{Ni}_{3} \mathrm{Al}$ and $\mathrm{Ni}_{3} \mathrm{Ga}$ can be explained solely by the larger $\mathrm{Ni} p$ DOS for the latter compound. For $\mathrm{Ni}_{3} \mathrm{Ga}$ and $\mathrm{NiGa}$, the unoccupied $\mathrm{Ga} p$ DOSs also affect the intensity variations of the features at roughly 4 and $13 \mathrm{eV}$ above the $\mathrm{Ga}-K$ white lines.

In Table II, we list the calculated and experimental values of the equilibrium lattice constants of these materials, along with their crystal structures. $\mathrm{Ni}_{3} \mathrm{Al}, \mathrm{Ni}_{3} \mathrm{Ga}$, and $\mathrm{Ni}_{3} \mathrm{In}$ have the cubic $L 1_{2}$ structure, while $\mathrm{NiGa}$ has the $\mathrm{B} 2$ structure. It was reported ${ }^{19}$ that $\mathrm{Ni}_{3}$ In has the ordered $D 0_{19}$ structure isotypic with $\mathrm{Ni}_{3} \mathrm{Sn}$. However, the $\mathrm{Ni} L_{2,3}$ XANES spectrum of $\mathrm{Ni}_{3}$ In calculated using this latter structure resulted in a much worse agreement with the experimental spectrum than using the cubic $L 1_{2}$ structure for $\mathrm{Ni}_{3} \mathrm{In} .{ }^{7}$ Our FLAPW results for the equilibrium lattice constants in Table II are within $1 \%$ of the experimental values, and weak ferromagnetism affects the structural properties of $\mathrm{Ni}_{3} \mathrm{Al}, \mathrm{Ni}_{3} \mathrm{Ga}$, and $\mathrm{Ni}_{3}$ In only slightly. The theoretical and experimental values of the bulk modulus $(B)$ for these intermetallic compounds are listed in the last column in Table II. Our calculated $B$ values for $\mathrm{Ni}_{3} \mathrm{Al}$ and $\mathrm{Ni}_{3} \mathrm{Ga}$ are about $8 \%$ and $25 \%$ larger than the experimental $B$ values for $\mathrm{Ni}_{3} \mathrm{Al}\left[1.707,{ }^{20} 1.71,{ }^{21}\right.$ and 1.73 (Ref. 22) Mbar] and $\mathrm{Ni}_{3} \mathrm{Ga}$ (1.46 Mbar), ${ }^{21}$ respectively. Here, only experimental $B$ values obtained from the stoichiometric single crystals at room temperature are used to compare with our calculated values, since it is reported ${ }^{23}$ that the elastic constants of nonstoichiometric polycrystals $\mathrm{Ni}_{3} \mathrm{Al}$ are rather different from each other and from those of $\mathrm{Ni}_{3} \mathrm{Al}$ single crystals. Our calculated $B$ value for $\mathrm{Ni}_{3} \mathrm{Al}$ (1.847 Mbar) agrees better with the experimental values than other theoretical calculated values $\left[1.75,{ }^{24,25} 1.743,{ }^{23} 2.10,{ }^{26}\right.$ and 2.34 (Ref. 27) Mbar] do. Our calculation for $\mathrm{Ni}_{3} \mathrm{Ga}$ overestimates the $B$ value by $25 \%$, which is much less than previous local spin-density approximation (LSDA) calculation (over 70\%) ${ }^{27}$ did. This means that it is important to include GGA in LSDA calculations. 
TABLE II. Crystal structure, lattice constant $a$, total magnetic moment $M_{s}$, density of states at the Fermi energy $n\left(E_{F}\right)$, and bulk modulus $B$ for $\mathrm{Ni}_{3} \mathrm{Al}, \mathrm{Ni}_{3} \mathrm{Ga}, \mathrm{Ni}_{3} \mathrm{In}$, and $\mathrm{NiGa}$. The first, second, and third line for each material is the theoretical (paramagnetic), theoretical (ferromagnetic), and experimental values, respectively.

\begin{tabular}{|c|c|c|c|c|c|}
\hline Material & Crystal structure & $a(\AA)$ & $M_{s}\left(\mu_{\mathrm{B}} /\right.$ cell $)$ & $n\left(E_{F}\right)($ states $/ \mathrm{eV}$ cell $)$ & $B$ (Mbar) \\
\hline \multirow{3}{*}{$\mathrm{Ni}_{3} \mathrm{Al}$} & $L 1_{2}$ & 3.571 & 0.0 & 5.82 & 1.863 \\
\hline & & 3.573 & 0.75 & 3.29 & 1.847 \\
\hline & & 3.568 & 0.23 & 11.02 & 1.707 \\
\hline \multirow[t]{3}{*}{$\mathrm{Ni}_{3} \mathrm{Ga}$} & $L 1_{2}$ & 3.589 & 0.0 & 6.66 & 1.836 \\
\hline & & 3.591 & 0.81 & 3.19 & 1.835 \\
\hline & & 3.576 & & 10.22 & 1.46 \\
\hline \multirow[t]{3}{*}{$\mathrm{Ni}_{3} \mathrm{In}$} & $L 1_{2}$ & 3.745 & 0.0 & 7.02 & 1.570 \\
\hline & & 3.747 & 0.73 & 4.66 & 1.564 \\
\hline & & 3.750 & & & \\
\hline \multirow[t]{3}{*}{$\mathrm{NiGa}$} & $B 2$ & 2.9231 & 0.0 & 0.87 & 1.530 \\
\hline & & 2.9230 & 0.0 & 0.87 & 1.522 \\
\hline & & 2.8952 & & 1.48 & \\
\hline
\end{tabular}

The magnetic properties of the intermetallic compounds we investigated in this work depend sensitively on the lattice constants, as shown in the fourth column in Table II for the total magnetic moments $\left(M_{s}\right)$. We note that our calculated $M_{s}$ value for $\mathrm{Ni}_{3} \mathrm{Al}\left(0.75 \mu_{\mathrm{B}} /\right.$ cell $)$ is three times larger than the experimental value $\left(0.23 \mu_{\mathrm{B}} /\right.$ cell $) .{ }^{1,28} \mathrm{An}$ attempt was made to include spin-orbit coupling in the self-consistent calculation for $\mathrm{Ni}_{3} \mathrm{Al}$, but no significant change of the $M_{s}$ value was observed. We should point out that LSDA and GGA calculations tend to overestimate the $M_{s}$ value for other materials, too. ${ }^{29}$ We should also mention that controversy has remained about the magnetic moment of $\mathrm{Ni}_{3} \mathrm{Al}$ with the $M_{s}$ values ranging from 0 to $0.7 \mu_{\mathrm{B}} / \mathrm{cell}^{29}$ The one $\left(0.71 \mu_{\mathrm{B}} / \text { cell }\right)^{26}$ closest to our value was calculated by means of the all-electron semirelativistic linear muffin-tin orbitals method. Since the ferromagnetic state is slightly lower in energy than the paramagnetic state by about 20 meV/cell for $\mathrm{Ni}_{3} \mathrm{Al}, \mathrm{Ni}_{3} \mathrm{Ga}$, and $\mathrm{Ni}_{3} \mathrm{In}$, all three materials should show weak itinerant ferromagnetism. This assertion agrees with that obtained from structural-stability study for $\mathrm{Ni}_{3} \mathrm{Al}^{26}$ However, experimentally $\mathrm{Ni}_{3} \mathrm{Ga}$ is an enhanced paramagnet. ${ }^{3}$ All these differences are a direct consequence of the small energy difference associated with magnetic polarization and the difficulty of conventional spin-polarized calculations to discriminate between nonmagnetic and ferromagnetic solutions. Magnetic measurements on $\mathrm{Ni}_{3} \mathrm{In}$ may be able to clarify the magnetic behavior of this material. $\mathrm{NiGa}$ on the other hand is paramagnetic. Site-decomposed magnetic moment at the $\mathrm{Ni}, \mathrm{Al}(\mathrm{Ga}, \mathrm{In})$, and interstitial sites for $\mathrm{Ni}_{3} \mathrm{Al}, \mathrm{Ni}_{3} \mathrm{Ga}$, and $\mathrm{Ni}_{3} \mathrm{In}$ are listed in the first row for each material in Table III. One can see that the main contribution for the magnetic moments of these three compounds comes from that of the Ni $3 d$ electrons; while uncompensated $\mathrm{Al} p$ electrons and electrons in the interstitial region are polarized slightly negatively.

The calculated and experimental DOSs at the Fermi energy $\left[n\left(E_{F}\right)\right]$ for $\mathrm{Ni}_{3} \mathrm{Al}, \mathrm{Ni}_{3} \mathrm{Ga}, \mathrm{Ni}_{3} \mathrm{In}$, and $\mathrm{NiGa}$ are listed in the fifth column in Table II, while the site-decomposed partial DOS at the Fermi energy are listed in the second and third rows for spin-up and spin-down band, respectively, in Table III. The main contribution for the $n\left(E_{F}\right)$ values for these compounds comes from the spin-down Ni $3 d$ electrons. For $\mathrm{Ni}_{3} \mathrm{Al}$ and $\mathrm{Ni}_{3} \mathrm{Ga}$, we chose the $n\left(E_{F}\right)$ values derived from the specific-heat measurement ${ }^{30}$ neglecting electron-phonon interaction as the experimental ones. The reason we chose these values in Table II is because the authors who reported these $n\left(E_{F}\right)$ values were the only ones that studied both compounds in the same paper. Higherexperimental $n\left(E_{F}\right)$ values $\left[12.86,{ }^{28} 13.08,{ }^{31}\right.$ and 13.84 (Ref. 32) $s$ tates/(eV cell)] derived from specific-heat measurements on $\mathrm{Ni}_{3} \mathrm{Al}$ were also reported. It should be pointed out that all the experimental $n\left(E_{F}\right)$ values for $\mathrm{Ni}_{3} \mathrm{Al}$ are much larger than our calculated paramagnetic one [5.82 states/(eV cell)], which is close to other theoretical paramagnetic values $\left[5.18,{ }^{33} 5.53,{ }^{34} 6.56,{ }^{27} 7.40,{ }^{26}\right.$ and 7.72 (Ref. 35$)$ states/(eV cell)]. Our ferromagnetic value for $\mathrm{Ni}_{3} \mathrm{Al}[3.29$ states/(eV cell)] is also close to other theoretical ferromagnetic ones [4.35 (Ref. 36) and 4.39 (Ref. 26) states/(eV cell)]. For $\mathrm{Ni}_{3} \mathrm{Ga}$, our calculated paramagnetic $n\left(E_{F}\right)$ value [6.66 states/(eV cell)] is essentially the same as previous theoretical ones $\left[5.45,{ }^{37} 6.25,{ }^{3}\right.$ and 6.47 (Ref. 35) states/(eV cell)]. However, all these theoretical values are much smaller than the experimental $n\left(E_{F}\right)$ values [9.71 (Ref. 38) and 10.22 (Ref. 31) states/(eV cell)]. The discrepancy between the $n\left(E_{F}\right)$ values calculated by band-structure calculations and those determined calorimetrically for $\mathrm{Ni}_{3} \mathrm{Al}$ and $\mathrm{Ni}_{3} \mathrm{Ga}$ is too

TABLE III. Magnetic moment $M_{s}$ (the first line in units of $\mu_{\mathrm{B}}$ /atom) and density of states at the Fermi energy $n\left(E_{F}\right)$ (the second and third lines for spin-up and spin-down states, respectively, in units of states/eV cell) at different sites for $\mathrm{Ni}_{3} \mathrm{Al}, \mathrm{Ni}_{3} \mathrm{Ga}$, and $\mathrm{Ni}_{3} \mathrm{In}$.

\begin{tabular}{cccr}
\hline \hline Material & Ni-site & $\mathrm{Al}(\mathrm{Ga}, \mathrm{In})$-site & Interstitial \\
\hline \multirow{2}{*}{$\mathrm{Ni}_{3} \mathrm{Al}$} & 0.27 & -0.03 & -0.04 \\
& 0.44 & 0.05 & 0.06 \\
& 2.62 & 0.05 & 0.07 \\
$\mathrm{Ni}_{3} \mathrm{Ga}$ & 0.29 & -0.02 & -0.04 \\
& 0.47 & 0.05 & 0.05 \\
& 2.48 & 0.06 & 0.08 \\
$\mathrm{Ni}_{3} \mathrm{In}$ & 0.267 & -0.02 & -0.05 \\
& 0.51 & 0.06 & 0.07 \\
& 3.85 & 0.06 & 0.11 \\
\hline \hline
\end{tabular}


large for any reasonable electron-phonon enhancement correction. The strong renormalization of these $n\left(E_{F}\right)$ values may point to the importance of exchange-enhanced spin fluctuations arising essentially from the effect of a molecular field which is local in space and time. ${ }^{3}$ For NiGa, the experimental $n\left(E_{F}\right)$ value $^{13}$ is also much larger than our calculated value. This latter discrepancy may be attributed to the electron-phonon mass enhancement. Further study is needed to explain these discrepancies found in the intermetallic compounds.

We also calculated the hole numbers in order to analyze charge transfer in these $\mathrm{Ni}$ intermetallic compounds. The number of $3 d$ holes per $\mathrm{Ni}$ atom calculated for $\mathrm{Ni}_{3} \mathrm{Al}$, $\mathrm{Ni}_{3} \mathrm{Ga}, \mathrm{Ni}_{3} \mathrm{In}$, and NiGa is $1.60,1.59,1.59$, and 1.49 , respectively. The hole number for bulk Ni calculated in this work is 1.44. As expected, the filling of the Ni $3 d$ bands in these compounds is incomplete. This conclusion is consistent with previous $\mathrm{x}$-ray photoemission spectroscopy, bremstrahlung isochromat spectroscopy, and resonent photoemission spectroscopy (RESPES) studies on these compounds. ${ }^{4,5}$ The changes in the number of $\mathrm{Ni} d$ electrons from bulk $\mathrm{Ni}$ to $\mathrm{Ni}_{3} \mathrm{Al}, \mathrm{Ni}_{3} \mathrm{Ga}$, and $\mathrm{Ni}_{3} \mathrm{In}$ are consistent with that $(0.1$ \pm 0.15 electrons/atom $)^{15}$ reported for other Ni compounds. One also finds that the hole number decreases in the series $\mathrm{Ni}, \mathrm{Ni}_{3} \mathrm{Al}, \mathrm{Ni}_{3} \mathrm{Ga}\left(\mathrm{Ni}_{3} \mathrm{In}\right)$, and $\mathrm{NiGa}$. Previous RESPES ${ }^{4}$ and core-level photoemission ${ }^{5}$ studies on these materials predicted the hole number decrease in the series bulk $\mathrm{Ni}$ (1.56), $\mathrm{Ni}_{3} \mathrm{Al}$ (1.37), $\mathrm{Ni}_{3} \mathrm{In}$ (1.34), and $\mathrm{Ni}_{3} \mathrm{Ga}$ (1.30). We note that the order for $\mathrm{Ni}_{3}$ In that obtained from the present theoretical calculation is not consistent with that obtained from previous experimental data. The maximum difference between these two sets of hole numbers for $\mathrm{Ni}_{3} \mathrm{Al}, \mathrm{Ni}_{3} \mathrm{Ga}$, and $\mathrm{Ni}_{3} \mathrm{In}$ is found for $\mathrm{Ni}_{3} \mathrm{In}$, and is only about $4 \%$. This observation seems to suggest that the uncertainty in determining the hole number for $\mathrm{Ni}_{3} \mathrm{In}$, both theoretically and experimentally, is higher than that for $\mathrm{Ni}_{3} \mathrm{Al}$ and $\mathrm{Ni}_{3} \mathrm{Ga}$. The higher uncertainty for $\mathrm{Ni}_{3} \mathrm{In}$ may be due to defects present in the sample.

It is well known that the cohesive energy can be predicted from the filling of the $d$ band, and a phenomenological relationship between the number of $3 d$ holes per Ni atom and the heat of formation $(\Delta H)$ was established recently for $\mathrm{Ni}_{3} \mathrm{Al}{ }^{10}$ Following Muller et al.'s method, ${ }^{10}$ we estimated that the $\Delta H$ values for $\mathrm{Ni}_{3} \mathrm{Al}, \mathrm{Ni}_{3} \mathrm{Ga}, \mathrm{Ni}_{3} \mathrm{In}$, and $\mathrm{NiGa}$ are $-0.48,-0.02,-0.06$, and $-0.14 \mathrm{eV} /$ atom, respectively. Therefore, the order of compound stability is $\mathrm{Ni}_{3} \mathrm{Al}, \mathrm{NiGa}$, $\mathrm{Ni}_{3} \mathrm{In}$, and $\mathrm{Ni}_{3} \mathrm{Ga}$. It is also worth noting that the general rule, ${ }^{39}$ that the strongest bond is for an exactly half-filled DOS, holds for the $\mathrm{Ni}-\mathrm{Ga}$ compounds. The $\Delta H$ values for $\mathrm{Ni}_{3} \mathrm{Al}$ and $\mathrm{Ni}_{3} \mathrm{In}$ are close to the experimental values of -0.43 and $-0.087 \pm 0.017 \mathrm{eV} /$ atom, respectively. ${ }^{40}$ There are two other reported $\Delta H$ values for $\mathrm{Ni}_{3} \mathrm{Al}$ : -0.41 (Ref. 41) and -0.40 (Ref. 42) eV/atom, which are within $7 \%$ to the above cited value. Surprisingly, the estimated $\Delta H$ value for $\mathrm{Ni}_{3} \mathrm{Al}$ is exactly the same as that calculated previously. ${ }^{26} \mathrm{We}$ also note that our calculated hole number per $\mathrm{Ni}$ atom for $\mathrm{Ni}_{3} \mathrm{Al}$ (1.36 in Table I) differs by only $2 \%$ with that (1.33) obtained previously. ${ }^{26}$ Thus, the simple approach used in this work is capable of predicting the heat of formation for these intermetallic compounds.

\section{CONCLUSIONS}

The electronic structures of $\mathrm{Ni}_{3} \mathrm{Al}, \mathrm{Ni}_{3} \mathrm{Ga}, \mathrm{Ni}_{3} \mathrm{In}$, and $\mathrm{NiGa}$ were studied jointly by XANES measurements at the $\mathrm{Ni}$ and $\mathrm{Ga} K$ edges and by theoretical analysis using FLAPW method. Except for NiGa, a reasonably good agreement between theory and experiment was found. The experimental XANES features for these compounds reflect the Ni-and Ga- $p$ unoccupied states. The disagreement between experimental and theoretical $\mathrm{Ni}$ and Ga $K$-edge XANES spectra found for NiGa is caused by a high concentration of antistructure defects present in the sample. The magnetic moments, the DOS at the Fermi energy, and the equilibrium lattice constants and bulk moduli for these intermetallics are calculated and compared with previous theoretical and experimental results. Discrepancies between calculated and experimental-derived DOS at the Fermi energy for these compounds come from electron-phonon mass enhancement and localized magnetic fluctuations. The number of $3 d$ holes per $\mathrm{Ni}$ atom is 1.36, 1.34, and 1.28 in the unoccupied bands of $\mathrm{Ni}_{3} \mathrm{Al}, \mathrm{Ni}_{3} \mathrm{Ga}$, and $\mathrm{Ni}_{3} \mathrm{In}$, respectively. These numbers show correlation with heats of formation of the bulk compounds.

\section{ACKNOWLEDGMENTS}

The authors thank J.-Y. Pieh and W.-F. Pong for EDX measurements, J.-F. Lee and C.-J. Chen for their help in data taking. This work was partially supported by grants from the National Science Council, Taiwan, Republic of China.

${ }^{1}$ F. R. De Boer, C. J. Schinkel, J. Biesterbos, and S. Proost, J. Appl. Phys. 40, 1049 (1969).

${ }^{2}$ N. Shiotani, C. R. Bull, R. N. West, N. Kawamiya, Y. Kubo, and S. Wakoh, J. Phys. Soc. Jpn. 55, 1961 (1986).

${ }^{3}$ N. R. Bernhoeft, G. G. Lonzarich, P. W. Mitchell, and D. Mck. Paul, Phys. Rev. Lett. 62, 657 (1989).

${ }^{4}$ L.-S. Hsu, K.-L. Tsang, and S.-C. Chung, in Applications of Synchrotron Radiation Techniques to Materials Science III, edited by L. J. Terminello, S. M. Mini, H. Ade, and D. L. Perry, Mater. Res. Soc. Symp. Proc. No. 437 (Materials Research Society, Pittsburgh, 1996), p. 53.

${ }^{5}$ W. F. Pong, K. P. Lin, Y. K. Chang, M.-H. Tsai, H. H. Hsieh, J. Y. Pieh, P. K. Tseng, J. F. Lee, and L.-S. Hsu, J. Synchrotron Radiat. 6, 731 (1999).

${ }^{6}$ Y. K. Chang, K. P. Lin, W. F. Pong, M.-H. Tsai, H. H. Hsieh, J. Y. Pieh, P. K. Tseng, J. F. Lee, and L.-S. Hsu, J. Appl. Phys. 87, 1312 (2000).

${ }^{7}$ L.-S. Hsu and A. I. Nesvizhskii, J. Phys. Chem. Solids 62, 1103 (2001).

${ }^{8}$ A. N. Mansour, A. Dmitrienko, and A. V. Soldatov, Phys. Rev. B 55, 15531 (1997).

${ }^{9}$ L.-S. Hsu, K.-L. Tsang, and S.-C. Chung, J. Magn. Magn. Mater. 177181, 1031 (1998).

${ }^{10}$ D. A. Muller, S. Subramanian, P. E. Batson, S. L. Sass, and J. Silcox, Phys. Rev. Lett. 75, 4744 (1995).

${ }^{11}$ D. A. Muller, D. J. Singh, and J. Silcox, Phys. Rev. B 57, 8181 (1998).

${ }^{12}$ L.-S. Hsu and R. S. Williams, J. Phys. Chem. Solids 55, 305 (1994).

${ }^{13}$ L.-S. Hsu, Y. D. Yao, and Y. Y. Chen, Mod. Phys. Lett. B 11, 407 (1997).

${ }^{14}$ P. Blaha, K. Schwarz, and J. Luitz, computer code WIEN97 (Vienna University of Technology, 1997). [Improved and updated UNIX version of the original copyrighted WIEN code, which was published by P. Blaha, K. Schwarz, P. Sorantin, and S. B. Trickey, in Comput. Phys. Commun. 59, 399 (1990)].

${ }^{15}$ J. P. Perdew, S. Burke, and M. Ernzerhof, Phys. Rev. Lett. 77, 3865 (1996).

${ }^{16}$ F. D. Murnaghan, Proc. Natl. Acad. Sci. U.S.A. 3, 244 (1944).

${ }^{17}$ P. E. Blochl, O. Jepsen, and O. K. Andersen, Phys. Rev. B 49, 16223 (1994).

${ }^{18}$ P. Horsch, W. von der Linden, and W.-D. Lukas, Solid State Commun. 62, 359 (1987). 
${ }^{19}$ Handbook of Lattice Spacings and Structures of Metals, edited by W. Pearson (Pergamon, New York, 1958).

${ }^{20}$ F. Wallow, G. Neite, W. Schroer, and E. Nembach, Phys. Status Solidi A 99, 483 (1987).

${ }^{21}$ H. Yasuda, T. Takasugi, and M. Koiwa, Acta Metall. Mater. 40, 381 (1992).

${ }^{22}$ F. X. Kayser and C. Stassis, Phys. Status Solidi A 64, 335 (1981).

${ }^{23}$ J. E. Osburn, M. J. Mehl, and B. M. Klein, Phys. Rev. B 43, 1805 (1991).

${ }^{24}$ S. M. Foiles and M. S. Daw, J. Mater. Res. 2, 5 (1987).

${ }^{25}$ C. L. Fu and M. H. Yoo, Philos. Mag. Lett. 58, 199 (1988).

${ }^{26}$ B. I. Min, T. Oguchi, H. J. F. Jansen, and A. J. Freeman, J. Magn. Magn. Mater. 54-57, 1091 (1986); J.-H. Xu, T. Oguchi, and A. J. Freeman, Phys. Rev. B 36, 4186 (1987); J.-H. Xu, B. I. Min, A. J. Freeman, and T. Oguchi, ibid. 41, 5010 (1990).

${ }^{27}$ D. Iotova, N. Kioussis, and S. P. Lim, Phys. Rev. B 54, 14413 (1996).

${ }^{28}$ N. Buis, J. J. M. Franse, and P. E. Brommer, Physica B \& C 106B, 1 (1981).

${ }^{29}$ V. L. Moruzzi and P. M. Marcus, Phys. Rev. B 42, 5539 (1990), and references therein.

${ }^{30}$ W. de Dood and P. F de Chatel, J. Phys. F: Met. Phys. 3, 1039 (1973).
${ }^{31}$ J. C. Ho, R. C. Liang, and D. P. Dandekar, J. Appl. Phys. 59, 1397 (1986).

${ }^{32}$ C. Stassis, F. X. Kayser, C.-K. Loong, and D. Arch, Phys. Rev. B 24, 3048 (1981).

${ }^{33}$ D. Hackenbracht and J. Kubler, J. Phys. F: Met. Phys. 10, 427 (1980).

${ }^{34}$ B. I. Min, A. J. Freeman, and H. J. F. Jansen, Phys. Rev. B 37, 6757 (1988).

${ }^{35}$ G. C. Fletcher, Physica (Amsterdam) 62, 41 (1972).

${ }^{36}$ J. J. M. Buiting, J. Kubler, and F. M. Mueller, J. Phys. F: Met. Phys. 13, L179 (1983).

${ }^{37}$ Y. Kubo and S. Wakoh, J. Phys. F: Met. Phys. 17, 397 (1987).

${ }^{38}$ E. Fawcett, J. P. Maita, E. Bucher, and J. H. Wernick, Phys. Rev. B 2, 3639 (1970).

${ }^{39}$ S. J. Pickart and R. Nathans, Phys. Rev. 123, 1163 (1961).

${ }^{40}$ R. Hultgren, P. D. Desai, D. T. Hawkins, M. Gleiser, and K. K. Kelley, Selected Values of the Thermodynamic Properties of Binary Alloys (American Society of Metals, Metals Park, OH, 1973).

${ }^{41}$ Smirthells Metals Reference Book, 6th ed., edited by E. A. Brandes (Butterworths, London, 1983).

${ }^{42}$ O. Kubaschewski, E. L. Evans, and C. B. Alcock, Metallurgical Thermochemistry, 4th ed. (Pergamon, Oxford, 1979). 